\title{
Pentanidium-Catalyzed Direct Assembly of Vicinal All-Carbon Quaternary Stereocenters through C(sp3)-C(sp3) Bond Formation
}

Choon-Hong Tan ( $\sim$ choonhong@ntu.edu.sg )

Nanyang Technological University

\section{Xu Ban}

Henan University

\section{Yifan Fan}

Henan University

\section{Tuan-Khoa Kha}

Nanyang Technological University

\section{Richmond Lee}

University of Wollongong

Choon Wee Kee

Institute of Chemical and Engineer Science https://orcid.org/0000-0003-1843-2189

\section{Zhiyong Jiang}

Henan Normal University

\section{Article}

Keywords: catalysis, assembly, carbon

Posted Date: February 23rd, 2021

DOl: https://doi.org/10.21203/rs.3.rs-250161/v1

License: (c) (i) This work is licensed under a Creative Commons Attribution 4.0 International License.

Read Full License 


\section{Pentanidium-Catalyzed Direct Assembly of Vicinal All-Carbon 2 Quaternary Stereocenters through $\mathbf{C}\left(\mathbf{s p}^{3}\right)-\mathrm{C}\left(\mathrm{sp}^{3}\right)$ Bond Formation}

3 Xu Ban, ${ }^{1,2}$ Yifan Fan, ${ }^{1}$ Tuan-Khoa Kha, ${ }^{2}$ Richmond Lee,,${ }^{3,4}$ Choon Wee Kee,,${ }^{2,5}$ Zhiyong Jiang, ${ }^{1 *}$ 4 Choon-Hong $\operatorname{Tan}^{2 *}$

$5{ }^{1}$ International Scientific and Technological Cooperation Base of Chiral Chemistry, Henan University, Kaifeng, Henan, P. R. 6 China 475004

$7 \quad{ }^{2}$ Division of Chemistry and Biological Chemistry, Nanyang Technological University, 21 Nanyang Link, Singapore 637371

$8{ }^{3}$ School of Chemistry and Molecular Bioscience, University of Wollongong, Northfields Avenue, Wollongong, NSW 2522,

9 Australia

$10{ }^{4}$ Molecular Horizons, University of Wollongong, Northfields Avenue, Wollongong, NSW 2522, Australia

$11 \quad{ }^{5}$ Process \& Catalysis Research, Institute of Chemical and Engineer Science, Singapore 627899

\section{Abstract}

The stereoselective construction of vicinal all-carbon quaternary stereocenters has long been a formidable synthetic challenge. Direct asymmetric coupling of a tertiary carbon nucleophile with a tertiary carbon electrophile is the most straightforward approach but it is sterically and energetically disfavored. Herein, we described a catalytic asymmetric substitution, where racemic tertiary bromides directly couple with racemic secondary or tertiary carbanion, creating a series of congested carbon $\left(\mathrm{sp}^{3}\right)$-carbon $\left(\mathrm{sp}^{3}\right)$ bonds, including isolated all-carbon quaternary stereocenters, vicinal tertiary/all-carbon quaternary stereocenters and vicinal all-carbon quaternary stereocenters. This double stereoconvergent process, using pentanidium as catalyst, affords substituted products in good enantioselectivities and diastereoselectivities.

\section{Introduction}

The use of high-throughput synthetic practices, in tandem with extensive use of Pd-coupling chemistry in medicinal chemistry laboratories world-wide, has led to a propensity of achiral, aromatic compounds in screening libraries. ${ }^{1}$ Many secondary metabolites with interesting pharmacological activities contain allcarbon quaternary stereocenters. ${ }^{2,3,4}$ Introducing all-carbon quaternary stereocenters into molecules will improve structural diversities in screening libraries. However, stereoselective construction of all-carbon quaternary stereocenters remains a significant challenge in synthetic chemistry. ${ }^{5,6}$ Amongst the limited 
number of strategies, for the formation of this highly congested moiety, double Heck coupling, ${ }^{7,8}$ double Aldol reaction, ${ }^{9}$ and double allylation ${ }^{10}$ have been reported to be useful (Figure 1a). Separately, the use of multi-substituted alkenes in [3+2] annulation, ${ }^{11,12}$ Diels-Alder ${ }^{13-15}$ and other cycloadditions ${ }^{16,17}$ is another common approach (Figure 1a). Recent advances include dearomatization addition of $\beta$-naphthols on 3bromooxindoles, ${ }^{18}$ Claisen rearrangement of $\gamma, \delta$-unsaturated carbonyl compounds, ${ }^{19}$ dialkylation of bisoxindoles, ${ }^{20}$ phosphine-catalyzed cyclization of allenes ${ }^{21}$ and a nucleophilic substitution at a quaternary carbon center with concomitant opening of a cyclopropane ring. ${ }^{22,23}$ On the other hand, direct radical coupling of two $\mathrm{C}\left(\mathrm{sp}^{3}\right)$ centers is a promising possibility as it can overcome steric hindrance; but currently it is limited to a narrow substrates scope such as bisoxindoles and chiral auxiliaries need to be deployed if enantioenriched compounds are required (Figure 1b). ${ }^{24-27}$ Thus far, there are no successful reports to prepare vicinal all-carbon quaternary stereocenters through a catalytic asymmetric coupling of two tertiary $\mathrm{C}\left(\mathrm{sp}^{3}\right)$ centers. This will be the most direct and convenient and yet, conceivably, the most sterically challenging approach. Nucleophilic substitution at a quaternary carbon center is difficult and can be made improbable if the nucleophile is also a bulky tertiary carbanion.

We have been developing chiral cationic salts such as pentanidium and bisguanidinium as phase transfer and ion-pair catalysts. ${ }^{28}$ Using these catalysts, we recently reported an enantioconvergent halogenophilic nucleophilic substitution $\left(\mathrm{S}_{\mathrm{N}} 2 \mathrm{X}\right)$ to generate enantioenriched quaternary stereocenters using thiols and azides. ${ }^{29-31}$ In a conventional $\mathrm{S}_{\mathrm{N}} 2$ substitution, the nucleophile displaces a carbon-bound leaving group $\mathrm{X}$, often a halogen, by attacking the carbon face opposite the C-X bond; while in the $\mathrm{S}_{\mathrm{N}} 2 \mathrm{X}$ reaction, the nucleophile approach a carbon-bound leaving group $\mathrm{X}$ from the front, making it an ideal stericallyimmune synthetic approach. Shortly thereafter, a more in-depth investigation of the azide-substitution with tertiary bromide, revealed that it is a dynamic kinetic resolution, modulated by base present in the reaction. ${ }^{32}$ Herein, we report our recent progress into the use of nucleophilic substitutions to construct vicinal all-carbon quaternary stereocenters, using insights from our previous works, through direct 
52 coupling of racemic tertiary electrophiles with racemic tertiary nucleophiles using chiral cations as

53 catalysts (Figure 1c).

(a) Major previous strategies

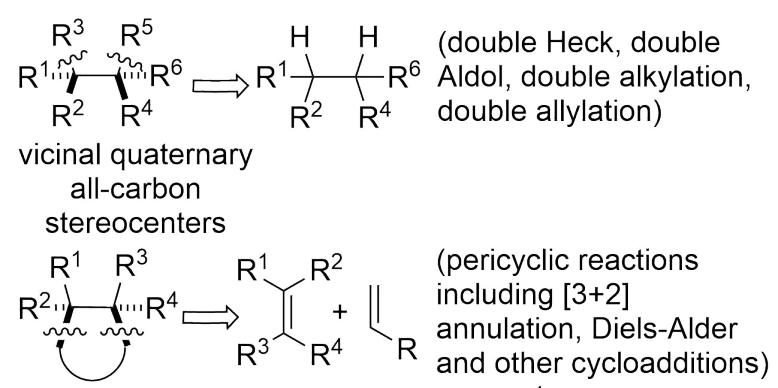

(b) Radical dimerizations<smiles>[R]C1N([R])c2ccccc2C1([R])[C@@]1([R])c2ccccc2N([R])C1[R]</smiles>

(c) This work: direct $\mathrm{C}\left(\mathrm{sp}^{3}\right)-\mathrm{C}\left(\mathrm{sp}^{3}\right)$ coupling

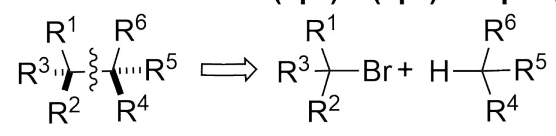

Figure 1 Major Strategies for Construction of Vicinal All-Carbon Quaternary Stereocenters

\section{Results and Discussions}

\section{Synthesis of Isolated All-Carbon Quaternary Stereocenters}

We began our investigation by extending our previous work on enantioconvergent $\mathrm{S}_{\mathrm{N}} 2 \mathrm{X}$ substitution.

Instead of thiols and azides, we wanted to demonstrate that carbon nucleophiles can add to racemic tertiary bromides. Firstly, methyl 2-bromo-2-cyanoacetate 1a was chosen as the model and various carbon pronucleophiles activated by an electron-withdrawing group such as acetophenone, isobutyronitrile and 2nitropropane, were examined under basic condition (Scheme 1a). We found that only protonated product 1a-H was obtained via a base-mediated $S_{N} 2 X$ debromination process. Further exploration revealed that carbon pronucleophiles with two electron withdrawing groups, such as malononitrile and dialkyl malonate, afforded the desired substituted products (Scheme 1b). 


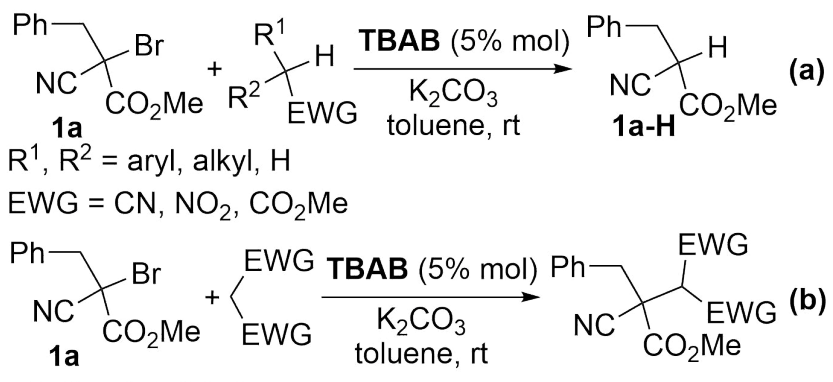

68 Subsequently, we found that in the presence of pentanidium PN1-3 or bisguanidinium BG1-3 as catalyst,

69 substituted product 2a was obtained with moderate yields and ee values (Table 1, entries 1-6).

70 Bisguanidinium BG1, bearing 3,5-bis(trifluoromethyl)benzyl groups, provided the most promising results

71 (entry 4). Further optimization by investigating various bases (entries 7-8), solvents (entries 9-11) and

72 temperature (entries 12-13) revealed that the ideal condition was using BG1 as catalyst, 4M aq. KOH (1.5

73 equiv.) as base in toluene at $-30{ }^{\circ} \mathrm{C}$. Lowering the reaction temperature further to $-40{ }^{\circ} \mathrm{C}$ led to a

74 significant decreased in yield, due to an increase formation of protonated product 1a-H (entry 13). When

75 methyl ester $\mathbf{1 a}$ is change to ethyl ester $\mathbf{1 b}$, ee value of adduct $\mathbf{2 b}$ is improved to $84 \%$ (entry 14). Further

76 increase in steric bulk of the tertiary bromides led to iso-propyl ester $\mathbf{2 c}$ and tert-butyl ester $\mathbf{2 d}$ with even

77 higher ee values (entries 15-16). However, changing dimethyl malonate to diethyl malonate or

78 diisopropyl malonate only led to an increased formation of $\mathbf{1 a - H .}$

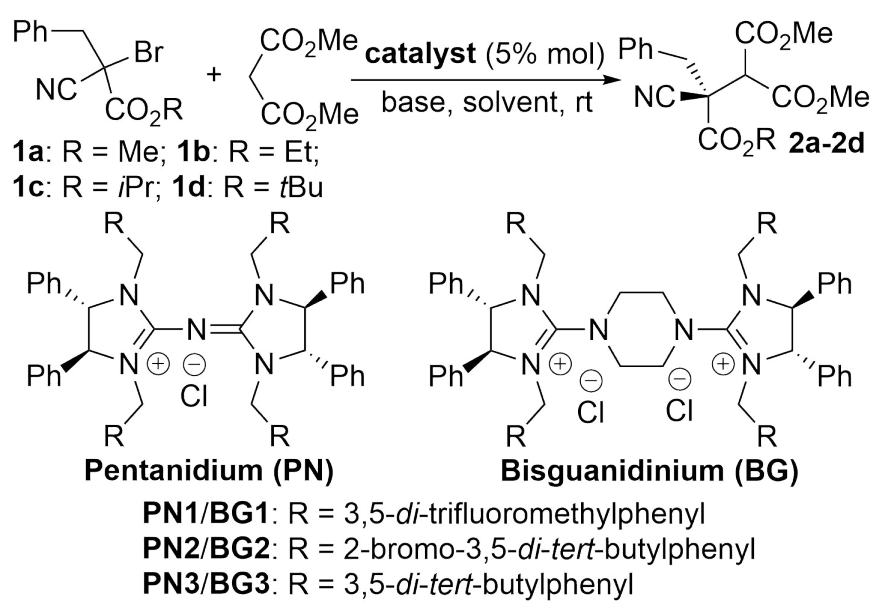


Table 1 Optimization of Reaction Conditions ${ }^{a}$

\begin{tabular}{|c|c|c|c|c|c|c|}
\hline entry & catalyst & base & solvent & 1 & $\begin{array}{l}\text { yield } \\
(\%)^{b}\end{array}$ & $\begin{array}{l}\mathrm{ee} \\
(\%)^{c}\end{array}$ \\
\hline 1 & PN1 & $\mathrm{K}_{2} \mathrm{CO}_{3}$ & toluene & $1 a$ & 78 & 57 \\
\hline 2 & PN2 & $\mathrm{K}_{2} \mathrm{CO}_{3}$ & toluene & $1 a$ & 80 & 54 \\
\hline 3 & PN3 & $\mathrm{K}_{2} \mathrm{CO}_{3}$ & toluene & $1 a$ & 82 & 46 \\
\hline 4 & BG1 & $\mathrm{K}_{2} \mathrm{CO}_{3}$ & toluene & $1 a$ & 82 & 62 \\
\hline 5 & BG2 & $\mathrm{K}_{2} \mathrm{CO}_{3}$ & toluene & $1 a$ & 80 & 55 \\
\hline 6 & BG3 & $\mathrm{K}_{2} \mathrm{CO}_{3}$ & toluene & $1 a$ & 82 & 45 \\
\hline 7 & BG1 & $\mathrm{Cs}_{2} \mathrm{CO}_{3}$ & toluene & $1 a$ & 84 & 62 \\
\hline 8 & BG1 & $\begin{array}{l}4 \mathrm{M} \text { aq. } \\
\mathrm{KOH}\end{array}$ & toluene & $1 a$ & 85 & 67 \\
\hline 9 & BG1 & $\begin{array}{l}4 \mathrm{M} \text { aq. } \\
\mathrm{KOH}\end{array}$ & $\mathrm{Et}_{2} \mathrm{O}$ & $1 a$ & 84 & 56 \\
\hline 10 & BG1 & $\begin{array}{l}4 \mathrm{M} \text { aq. } \\
\mathrm{KOH}\end{array}$ & THF & $1 a$ & 85 & 25 \\
\hline 11 & BG1 & $\begin{array}{l}4 \mathrm{M} \text { aq. } \\
\mathrm{KOH}\end{array}$ & DCM & $1 a$ & 78 & 20 \\
\hline $12^{d}$ & BG1 & $\begin{array}{l}4 \mathrm{M} \text { aq. } \\
\mathrm{KOH}\end{array}$ & toluene & $1 a$ & 85 & 75 \\
\hline $13^{e}$ & BG1 & $\begin{array}{l}4 \mathrm{M} \text { aq. } \\
\mathrm{KOH}\end{array}$ & toluene & $1 a$ & 47 & 78 \\
\hline $14^{d}$ & BG1 & $\begin{array}{l}4 \mathrm{M} \text { aq. } \\
\mathrm{KOH}\end{array}$ & toluene & $1 b$ & 84 & 86 \\
\hline $15^{d}$ & BG1 & $\begin{array}{l}4 \mathrm{M} \text { aq. } \\
\mathrm{KOH}\end{array}$ & toluene & 1c & 80 & 89 \\
\hline $16^{d}$ & BG1 & $\begin{array}{l}4 \mathrm{M} \text { aq. } \\
\mathrm{KOH}\end{array}$ & toluene & 1d & 78 & 94 \\
\hline
\end{tabular}

$81{ }^{a}$ Unless otherwise noted, reactions were carried out with catalyst (5 mol \%), 1a-d $(0.05 \mathrm{mmol})$, dimethyl malonate

82 (0.06 mmol), base $(0.07 \mathrm{mmol})$ in solvent $(2 \mathrm{~mL})$ at room temperature. ${ }^{b}$ Isolated yield of $2 \mathrm{a}-\mathrm{d}$. ${ }^{c}$ Determined by

83 HPLC using chiral column. ${ }^{d}$ Reactions for 2 days at $-30{ }^{\circ} \mathrm{C} .{ }^{e}$ Reactions for 2 days at $-40{ }^{\circ} \mathrm{C}$.

84 Under the ideal set of conditions developed above, various tertiary bromides 3d-16d were further

85 evaluated (Figure 2). Both electron-withdrawing group and electron-donating groups of the benzyl-

86 substituted substrates were tolerated (2e-2i). Replacing the phenyl group with a naphthyl group, thiophene

87 or pyridine also resulted in good yields and ee values of the adducts $2 \mathbf{j}$ and $\mathbf{2 k}, \mathbf{2 l}$ respectively. Tertiary

88 bromides with alkyl groups can afford the desired substituted adducts in good yields and ee (2m-2n). The

89 reaction was also effective for tertiary bromides bearing allylic or alkene substituents (2o-2q). 


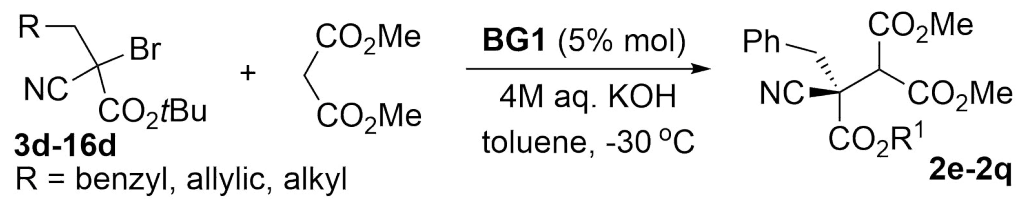<smiles>[R]c1ccc(C[C@](C)(C(C(C)=O)C(C)=O)C(C)(C)C)cc1</smiles>

2e, $\mathrm{R}^{\prime}=\mathrm{F} ; 75 \%$ yield, $96 \%$ ee

2f, $\mathrm{R}^{\prime}=\mathrm{Cl} ; 75 \%$ yield, $90 \%$ ee

2g, R' = Br; $77 \%$ yield, $92 \%$ ee

2h, R' $=\mathrm{NO}_{2} ; 70 \%$ yield, $88 \%$ ee

$\mathbf{2 i}, \mathrm{R}^{\prime}=\mathrm{OMe} ; \mathbf{7 7} \%$ yield, $90 \%$ ee
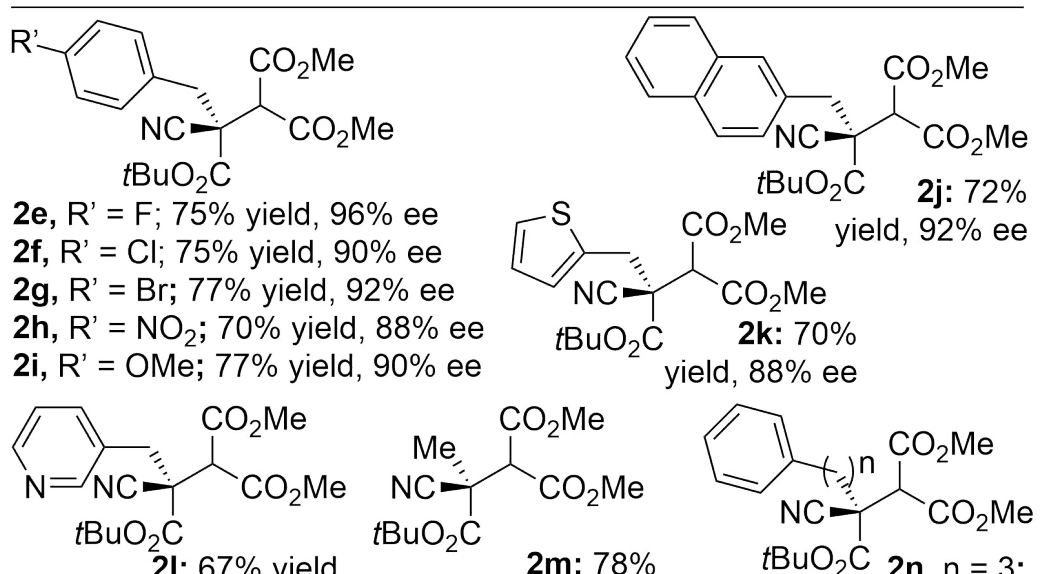<smiles>COC(=O)C(C)(C)C(C)(C)OC(C)(C)C</smiles>
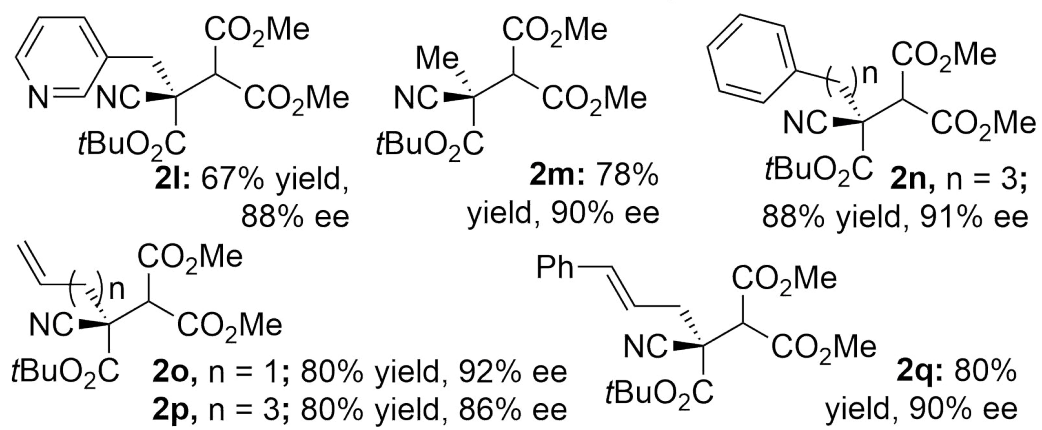

2m: $78 \%$ $88 \%$ yield, $91 \%$ ee

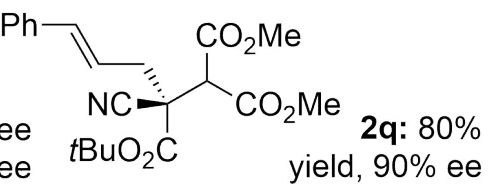

Figure 2 Synthesis of Isolated All-Carbon Quaternary Stereocenters. Unless otherwise noted, the reactions were carried out with BG1 (5 mol \%), 4M aq. $\mathrm{KOH}(0.07 \mathrm{mmol})$, tertiary bromides 3d-16d $(0.05 \mathrm{mmol})$, dimethyl malonate $(0.06 \mathrm{mmol})$ in toluene $(2 \mathrm{~mL})$ at $-30{ }^{\circ} \mathrm{C}$ for $2-3$ days. Isolated yields are reported. The ee values were determined by HPLC analysis on chiral stationary phase. Absolute configuration was determined using an X-ray crystal structure of $\mathbf{2 1} . \mathrm{HCl}$ (See SI, page 80 ).

\section{6 Synthesis of Vicinal Tertiary/All-Carbon Quaternary Stereocenters}

97

Following the success of generating enantioenriched quaternary carbon centers through the addition of dimethyl malonate to racemic tertiary bromides, we wonder if significant diastereoselectivity will be observed when esters groups on malonates were different. Thus, tertiary bromide 1a was treated with ethyl methyl malonate 18a (Table 2, entry 1); it was found, after screening our catalyst library, that PN1 can provide adduct 19a with moderate enantioselectivity and some diastereoselectivity. By introducing $i \operatorname{Pr}(\mathbf{1 8 b}), \mathrm{Bn}(\mathbf{1 8 c})$ or $t \mathrm{Bu}(\mathbf{1 8 d})$ groups to monomethyl malonates to increase steric discrimination, we found that diastereoselectivities increased correspondingly (entries 2-4). However, using ethyl iso-propyl malonate 18e did not further improve the diastereoselectivity observed and the yield decreased dramatically (entry 5). When ethyl tert-butyl malonate $\mathbf{1 8 f}$ was used, mostly protonated product $\mathbf{1 a - H}$ was 
106 obtained (entry 6). Thiolate $\mathbf{1 8 g}$ produced the corresponding adduct but ee and dr values obtained were

107 moderate (entry 7). Amide $\mathbf{1 8 h}$ was also examined but no desired adduct was observed (entry 8). Further

108 investigations were conducted with methyl tert-butyl malonate 18d (entries 9-11) by varying different

109 bromides and found 1d gave 19k the best results with 90\% ee and 49:1 dr (entry 11).

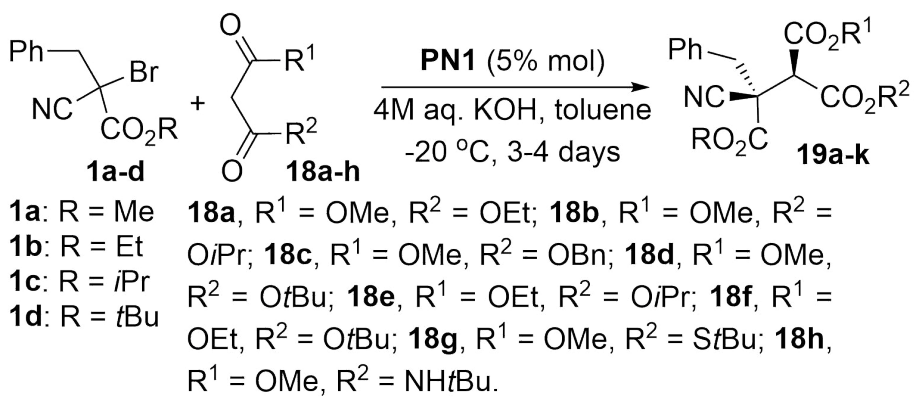

Table 2 Optimization of Reaction Conditions ${ }^{a}$

\begin{tabular}{llllll}
\hline entry & 1 & 18 & $\begin{array}{l}\text { yield } \\
(\%)^{b}\end{array}$ & $\begin{array}{l}\mathrm{ee} \\
(\%)^{c}\end{array}$ & $\mathrm{dr}^{d}$ \\
\hline 1 & 1a & $\mathbf{1 8 a}$ & 87 & 60 & $1.2: 1$ \\
2 & $\mathbf{1 a}$ & $\mathbf{1 8 b}$ & 82 & 72 & $2: 1$ \\
3 & $\mathbf{1 a}$ & $\mathbf{1 8 c}$ & 85 & 55 & $2: 1$ \\
4 & $\mathbf{1 a}$ & $\mathbf{1 8 d}$ & 85 & 78 & $4: 1$ \\
5 & $\mathbf{1 a}$ & $\mathbf{1 8 e}$ & 60 & 76 & $2: 1$ \\
6 & $\mathbf{1 a}$ & $\mathbf{1 8 f}$ & trace & -- & -- \\
7 & 1a & $\mathbf{1 8 g}$ & 81 & 54 & $4: 1$ \\
8 & 1a & $\mathbf{1 8 h}$ & trace & -- & -- \\
9 & 1b & $\mathbf{1 8 d}$ & 82 & 84 & $8: 1$ \\
10 & 1c & $\mathbf{1 8 d}$ & 80 & 89 & $9: 1$ \\
11 & 1d & $\mathbf{1 8 d}$ & 80 & 90 & $49: 1$ \\
\hline
\end{tabular}

$112{ }^{a}$ Unless otherwise noted, reactions were carried out with PN1 (5 mol \%), bromide 1a-d $(0.05 \mathrm{mmol})$, malonate 18a$113 \mathbf{h}(0.0 .06 \mathrm{mmol}), 4 \mathrm{M}$ aq. $\mathrm{KOH}(0.05 \mathrm{mmol})$ in toluene $(2 \mathrm{~mL})$ at $-20{ }^{\circ} \mathrm{C}$ for 2 days. ${ }^{b}$ Isolated yield of 19. ${ }^{c}$ 114 Determined by HPLC using chiral column. ${ }^{d}$ Determined HPLC analysis.

115 With this optimized reaction conditions in hand, various tertiary bromides were studied (Figure 3).

116 Tertiary bromides with benzylic substitutions, heterocycles, alkyl and allylic substituents that were

117 investigated, afforded their corresponding adducts 19l-19s in good yields and stereoselectivity. 


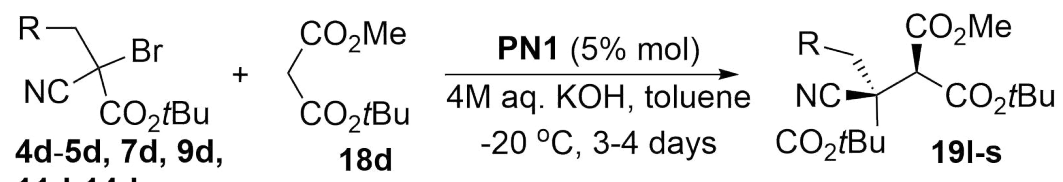




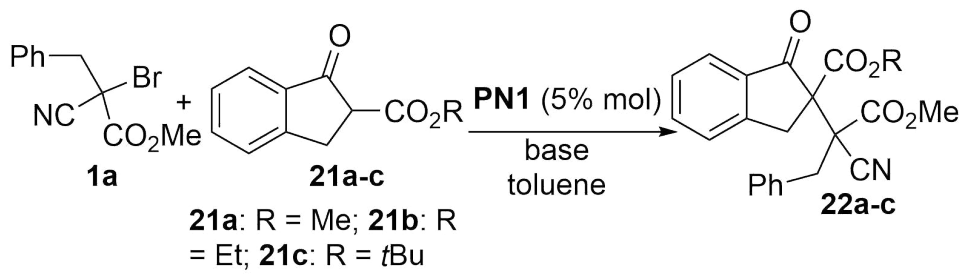

\begin{tabular}{llllll}
\hline entry & 21 & base & $\begin{array}{l}\text { yield } \\
(\%)^{b}\end{array}$ & $\begin{array}{l}\text { ee } \\
(\%)^{c}\end{array}$ & $\mathrm{dr}^{d}$ \\
\hline 1 & 21a & $\begin{array}{l}4 \mathrm{M} \\
\text { aq.KOH }\end{array}$ & 60 & 45 & $2: 1$ \\
2 & 21b & $\begin{array}{l}4 \mathrm{M} \\
\text { aq.KOH }\end{array}$ & 50 & 53 & $2: 1$ \\
3 & 21c & $\begin{array}{l}4 \mathrm{M} \\
\text { aq.KOH }\end{array}$ & 53 & 62 & $6: 1$ \\
4 & 21c & $\mathrm{LiOH}$ & 34 & 60 & $5: 1$ \\
5 & 21c & $\mathrm{NaOH}$ & 17 & 56 & $6: 1$ \\
6 & 21c & $\mathrm{KOH}_{7}$ & 23 & 67 & $6: 1$ \\
7 & 21c & $\mathrm{Na}_{2} \mathrm{CO}_{3}$ & 45 & 70 & $5: 1$ \\
8 & 21c & $\mathrm{K}_{2} \mathrm{CO}_{3}$ & 76 & 70 & $5: 1$ \\
9 & 21c & $\mathrm{Cs}_{2} \mathrm{CO}_{3}$ & 84 & 72 & $6: 1$ \\
10 & 21c & $\mathrm{K}_{3} \mathrm{PO}_{4}$ & 78 & 70 & $6: 1$ \\
$11^{\mathrm{e}}$ & 21c & $\mathrm{Cs}_{2} \mathrm{CO}_{3}$ & 83 & 84 & $10: 1$ \\
\hline
\end{tabular}

a Unless otherwise noted, reactions were carried out with PN1 (5 mol \%), 1a $(0.1 \mathrm{mmol}), 21 \mathrm{a}-\mathrm{c}(0.12 \mathrm{mmol})$, base $(0.15 \mathrm{mmol})$ in toluene $(2 \mathrm{~mL})$ at room temperature for $3-4$ days. ${ }^{b}$ Isolated yield. ${ }^{c}$ Determined by HPLC using chiral column. ${ }^{d}$ Determined HPLC analysis. ${ }^{e}$ Reaction temperature is $-20{ }^{\circ} \mathrm{C}$.

Subsequently, we identified cyclic $\beta$-ketone ester 21a as a suitable model to study this reaction (Table 3 ).

It allowed the coupling with tertiary bromide 1a to proceed (entry 1). From our previous studies, we concluded that steric effect played a crucial role in enantioselectivity and diastereoselectivity. When tertiary bromide $\mathbf{1 b}$ was investigated, we found that it led to an increased yield of protonated product and with tertiary bromide 1c, no desired product was obtained. On the other hand, changing cyclic $\beta$-ketone ester 21 led to more interesting results. When tert-butyl ester 21c was used, both ee and dr values of the corresponding adduct were increased (Table 3, entries 1-3). We hypothesized that the protonated product could be suppressed if we removal of water from the reaction condition. Thus, in order to improve the yield of adduct 22, we need to choose a more suitable base. We investigated a series of bases ranging 

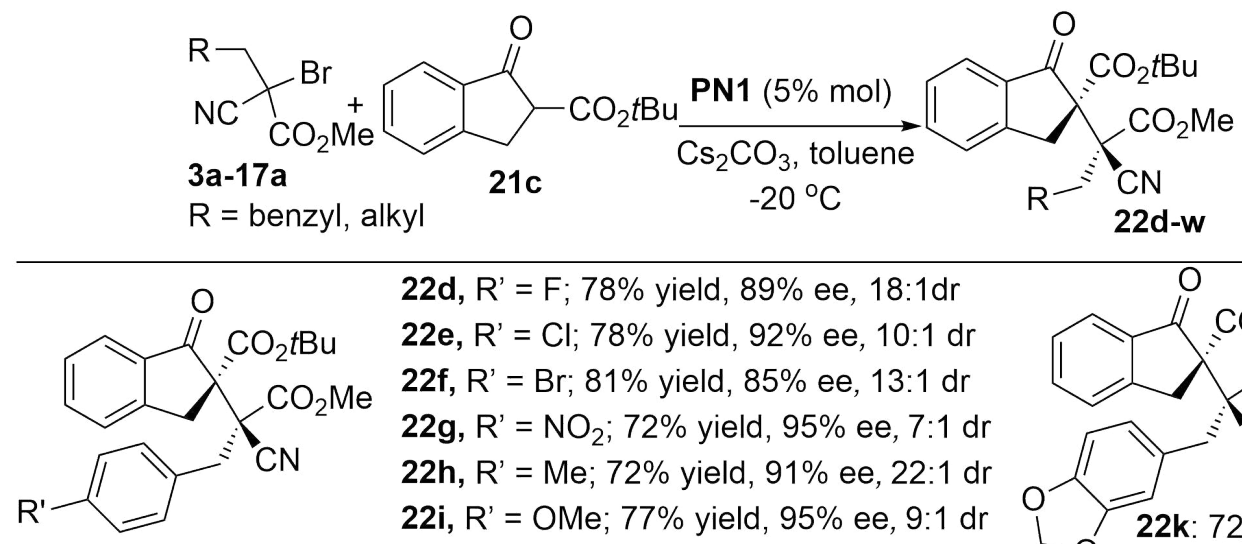

22d, R' = F; 78\% yield, 89\% ee, 18:1dr

22e, $\mathrm{R}^{\prime}=\mathrm{Cl}$; $78 \%$ yield, $92 \%$ ee, $10: 1 \mathrm{dr}$ 22f, R' = Br; $81 \%$ yield, $85 \%$ ee, $13: 1 \mathrm{dr}$ 22g, R' $=\mathrm{NO}_{2} ; 72 \%$ yield, $95 \%$ ee, $7: 1 \mathrm{dr}$ 22h, R' = Me; $72 \%$ yield, $91 \%$ ee, $22: 1 \mathrm{dr}$<smiles>CCOC(=O)C1(C(C)(C#N)Cc2cccs2)Cc2ccccc2C1=O</smiles>
22i, R' = OMe; $77 \%$ yield, $95 \%$ ee, $9: 1 \mathrm{dr}$ 22j, R' $=$ SMe; $77 \%$ yield, $90 \%$ ee, 9:1 dr<smiles>COOC(C)(C#N)[C@]1(Cc2ccc3c(c2)OCO3)Cc2ccccc2C1=O</smiles>

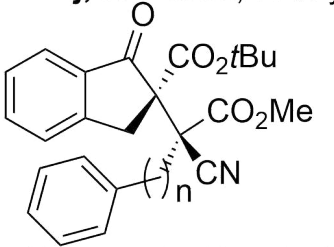
$93 \%$ ee, $49: 1 \mathrm{dr}$ $22 \mathrm{~m}, \mathrm{n}=3 ; 76 \%$ yield<smiles>COC(=O)C1(C(C)(C)C)Cc2ccccc2C1=O</smiles><smiles>CCOC(=O)C(C)(C)[C@@]1(C(=O)OCC)Cc2ccccc2C1=O</smiles>
$96 \%$ yield, $87 \%$ ee, $13: 1 \mathrm{dr}$ , $15: 1 \mathrm{dr}$

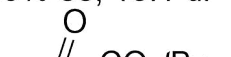<smiles>CCOC(=O)C1(C(C)C)Cc2cc(C)ccc2C1=O</smiles>
$76 \%$ yield, $88 \%$ ee, $9: 1 d r$<smiles>CCOC(=O)C(C)(C)[C@@]1(C(=O)OCC)Cc2ccc(C)cc2C1=O</smiles>

Figure 4 Synthesis of Vicinal All-Carbon Quaternary Stereocenters. Unless otherwise noted, the reactions were carried out with PN1 (5 mol \%), $\mathrm{Cs}_{2} \mathrm{CO}_{3}(0.07 \mathrm{mmol}), \mathbf{1 a}(0.05 \mathrm{mmol}), 21 \mathrm{c}(0.06 \mathrm{mmol})$ in toluene $(2 \mathrm{~mL})$ at $-20{ }^{\circ} \mathrm{C}$ (See SI, page 85). 
159 With the goldilocks zone identified, we expanded investigation of the scope of the tertiary bromides that

160 we can used. We report successful cases, which the reaction proceeded smoothly with good yields and

161 stereoselectivities (Figure 4, 22d-w). For benzyl substitutions in bromides, both electron-withdrawing and

162 electron-donating groups were tolerated (22d-k). Heterocycle such as thiophene was well tolerated (221).

163 Simple alkyl groups also produced good results (22m-p). Olefin containing alkyl chains were transformed

164 into the desired product with good yields and stereoselectivities (22q). Substitution on cyclic $\beta$-ketone

165 ester 21e-f was also well tolerated (22r-w). Attempts to expand to other tertiary carbon nucleophiles such

166 as tert-butyl 1-oxo-1,2,3,4-tetrahydronaphthalene-2-carboxylate and tert-butyl 2-oxocyclopentane-1-

167 carboxylate were not successful. We continue to explore other potential tertiary carbon nucleophiles.

\section{Mechanistic Study}

(a) Carbanion-exchange experiment
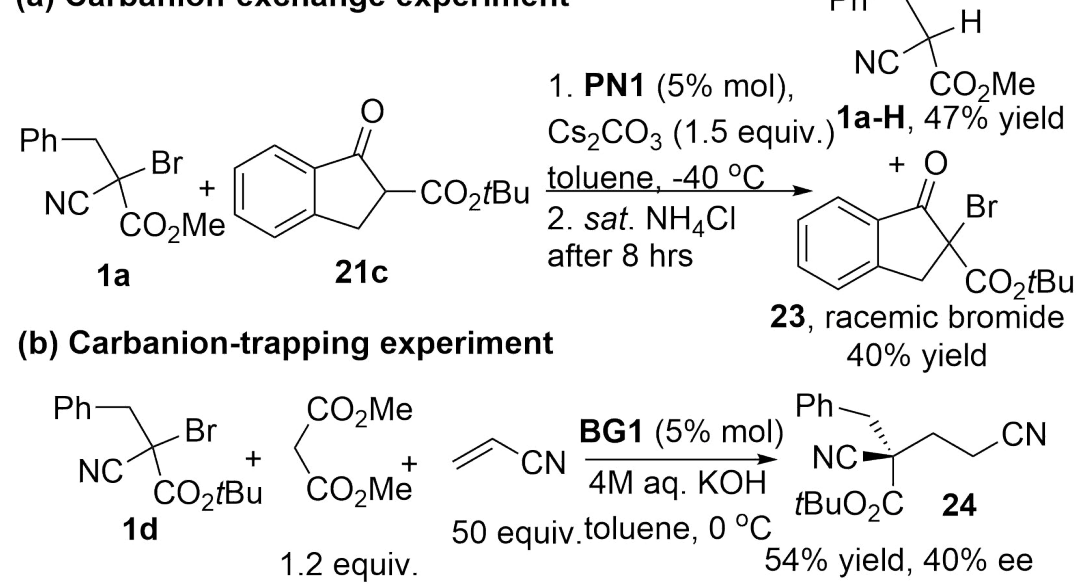

(c) Reactions with enantioenriched tertiary bromides

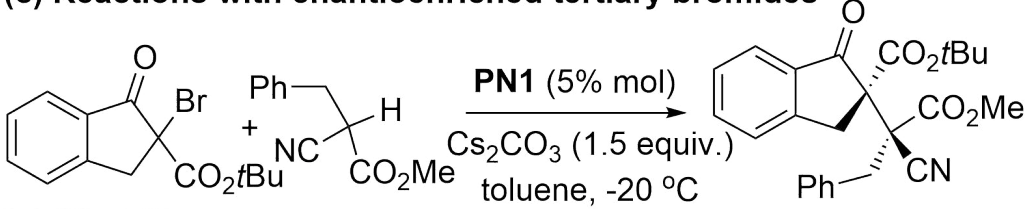
(+)-23, $57 \%$ ee
22c: $78 \%$ yield, $87 \%$ ee, $9: 1 \mathrm{dr}$
(-)-23, 45\% ee
22c: $75 \%$ yield, $85 \%$ ee, $9: 1 \mathrm{dr}$

(d) Base-mediated racemization

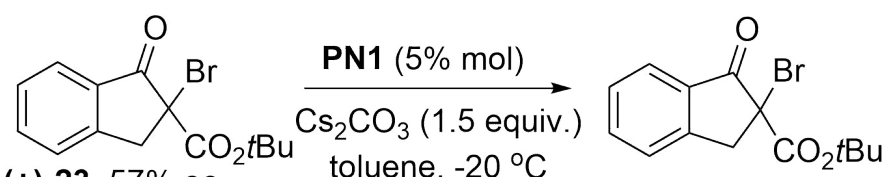

(+)-23, 57\% ee

(-)-23, $45 \%$ ee

23, racemized bromide 
171 In order to gain a better understanding of the mechanism, control experiments were designed accordingly.

172 Firstly, a carbanion-exchange experiment was conducted between tertiary bromide 1a and cyclic

$173 \beta$-ketone ester 21c. The reaction temperature was lowered from $-20{ }^{\circ} \mathrm{C}$ to $-40{ }^{\circ} \mathrm{C}$ and the reaction was 174 quenched using sat. $\mathrm{NH}_{4} \mathrm{Cl}$ after 8 hours. The transfer of $\mathrm{Br}$ atom from 1a to 21c was evident through the 175 significant production bromide 23 (Scheme 3a). However, both protonated product $\mathbf{1 a - H}$ and bromide $\mathbf{2 3}$

176 were obtained as racemic mixtures. Separately, a carbanion-trapping experiment using acrylonitrile,

177 further substantiate the presence of a carbanion intermediate, generated from tertiary bromide 1d (Scheme

$1783 b$ ). The conjugated addition product 24 was obtained with moderate enantioselectivity, pointing to close

179 ion-pair interaction of the carbanion with bisguanidinium BG1. Next, we prepared the enantioenriched 180 tertiary bromide $\mathbf{2 3}$ by using preparative high-performance liquid chromatography and subjected them to 181 our conditions separately (Scheme 3c). We found that both enantioenriched tertiary bromides 23 were 182 transformed to the same stereoisomer 22c. Lastly, a base mediated racemization was observed when 183 treating enantioenriched bromides 23 with $\mathrm{Cs}_{2} \mathrm{CO}_{3}$, this indicated a $\mathrm{Cs}_{2} \mathrm{CO}_{3}$ induced dynamic kinetic 184 resolution prior the $\mathrm{C}-\mathrm{C}$ bond coupling, which contributes to the high stereoselectivity (Scheme 3d). 185 Based on previous investigations (Scheme 4a) and our preliminary studies, we proposed that cyclic $\beta$ 186 ketone ester 21c and tertiary bromide underwent carbanion-exchange through $\mathrm{S}_{\mathrm{N}} 2 \mathrm{X}$ (Scheme $4 b$ ). Cyclic $187 \quad \beta$-ketone ester bromide 23 that is generated in this step can undergo further racemization through $\mathrm{S}_{\mathrm{N}} 2 \mathrm{X}$ 188 that is modulated by base. Finally, $\mathrm{S}_{\mathrm{N}} 2$ substitution occurred between the PN1 paired carbanion generated 189 from tertiary bromide $\mathbf{A}$ and cyclic $\beta$-ketone ester bromide $\mathbf{2 3}$ to install the vicinal all-carbon quaternary 190 stereocenters through the coupling of two $\mathrm{C}\left(\mathrm{sp}^{3}\right)$ centers.

191 Conclusions

192 In conclusion, we have successfully developed the pentanidium-catalyzed direct coupling of tertiary 193 carbon nucleophiles and tertiary carbon electrophiles through $\mathrm{C}\left(\mathrm{sp}^{3}\right)-\mathrm{C}\left(\mathrm{sp}^{3}\right)$ bond formation. These 194 reactions allowed the direct construction of the challenging vicinal all-carbon quaternary stereocenters in 
high efficiencies. This transformation is so far the most efficient approach for assembling this congested $\mathrm{C}\left(\mathrm{sp}^{3}\right)-\mathrm{C}\left(\mathrm{sp}^{3}\right)$ bond. Synthetic application of this new methodology is currently ongoing in our group.

(a) Previous work on $S_{N} 2 X$ reaction

$\mathrm{S}_{\mathrm{N}} 2 \mathrm{X}$ substitution

Dynamic kinetic resolution
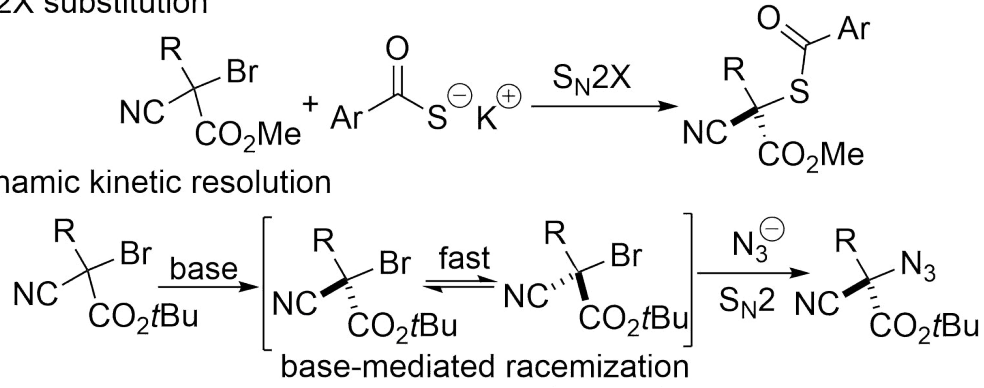

(b) Proposed mechanism for direct $\mathrm{C}\left(\mathrm{sp}^{3}\right)-\mathrm{C}\left(\mathrm{sp}^{3}\right)$ coupling
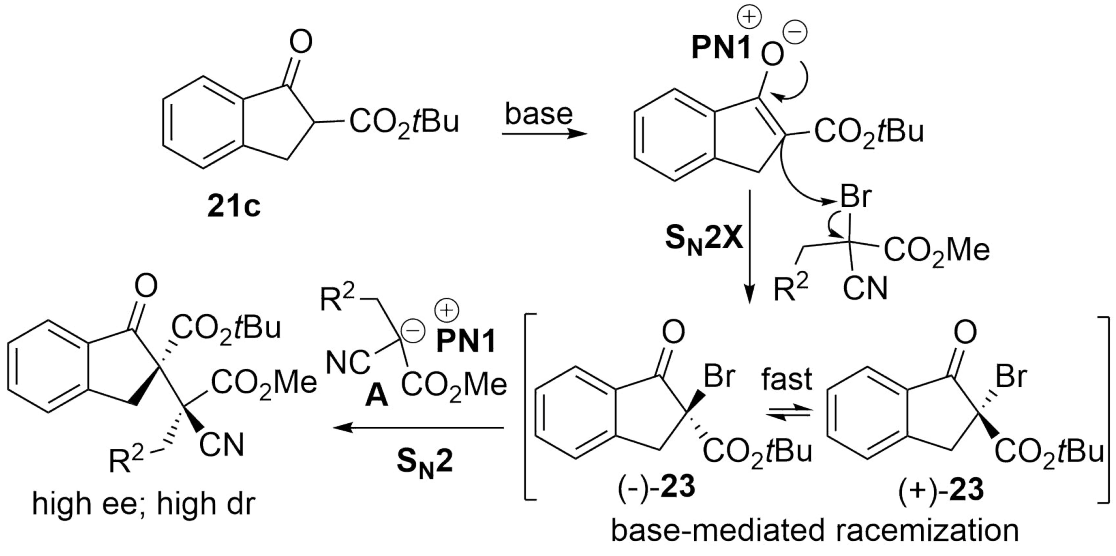

\section{Methods}

1. General procedure for the synthesis of chiral isolated all-carbon quaternary stereocenters: the bromide (1.0 equiv.), dimethyl carbonate (1.2 equiv.) and BG1 (5\% mol) were dissolved in toluene, cooling down the reaction mixture to $-30{ }^{\circ} \mathrm{C}$, and then $4 \mathrm{M}$ aq. $\mathrm{KOH}$ was added by a micro syringe. The mixture was stirred at $-30{ }^{\circ} \mathrm{C}$ for $2-3$ days until the completion. TLC monitored the process. The reaction was quenched with $\mathrm{NH}_{4} \mathrm{Cl}(1 \mathrm{~mL})$ and then water $(10 \mathrm{~mL})$ was added. Separate the organic phase and extract aqueous phase with DCM. The combined organic phase was washed with brine, 
chromatography (hexane: ether $=5: 1$ as the eluent) to get the chiral isolated all-carbon quaternary stereocenters.

2. General procedure for the synthesis of vicinal tertiary and quaternary stereocenters: the bromide (1.0 equiv.), dimethyl carbonate (1.2 equiv.) and PN1 (5\% mol) were dissolved in toluene, cooling down the reaction mixture to $-20{ }^{\circ} \mathrm{C}$, and then $4 \mathrm{M}$ aq. $\mathrm{KOH}$ was added by a micro syringe. The mixture was stirred at $-20{ }^{\circ} \mathrm{C}$ for $3-4$ days until the completion. TLC monitored the process. The reaction was quenched with $\mathrm{NH}_{4} \mathrm{Cl}(1 \mathrm{~mL})$ and then water $(10 \mathrm{~mL})$ was added. Separate the organic phase and extract aqueous phase with DCM. The combined organic phase was washed with brine, dried over anhydrous $\mathrm{Na}_{2} \mathrm{SO}_{4}$, filtered, and concentrated. The residue was purified by flash chromatography (hexane: ether $=5: 1$ as the eluent) to get the chiral vicinal tertiary and quaternary stereocenters. One of the chiral centers which bears an acidic proton is not stable, and can be racemized with excess base. After purification, the sample should be kept in $-20^{\circ} \mathrm{C}$ fridge.

3. General procedure for the synthesis of vicinal all-carbon quaternary stereocenters: the bromide (1.0 equiv.), dimethyl carbonate (1.2 equiv.) and PN1 (5\% mol) were dissolved in Toluene, cooling down the reaction mixture to $-20{ }^{\circ} \mathrm{C}$, and then $\mathrm{Cs}_{2} \mathrm{CO}_{3}$ (1.5 equiv.) was added in one portion. The mixture was stirred at $-20{ }^{\circ} \mathrm{C}$ for 3-4 days until the completion. TLC monitored the process. The reaction was quenched with $\mathrm{NH}_{4} \mathrm{Cl}(1 \mathrm{~mL})$ and then water $(10 \mathrm{~mL})$ was added. Separate the organic 224 phase and extract aqueous phase with DCM. The combined organic phase was washed with brine, dried over anhydrous $\mathrm{Na}_{2} \mathrm{SO}_{4}$, filtered, and concentrated. The residue was purified by flash stereocenters. 


\section{Data availability}

229 The authors declare that all other data supporting the findings of this study are available within the article

230 and Supplementary Information files, and also are available from the corresponding author upon

231 reasonable request. The X-ray crystallographic coordinates for structures reported in this study have been

232 deposited at the Cambridge Crystallographic Data Centre (CCDC).

\section{References}

234 1. Lovering, F.; Bikker, J.; Humblet, C. Escape from Flatland: Increasing Saturation as an Approach to 235 Improving Clinical Success J. Med. Chem. 52, 6752-6756, (2009).

236 2. Steven, A.; Overman, L. E. Total Synthesis of Complex Cyclotryptamine Alkaloids: Stereocontrolled 237 Construction of Quaternary Carbon Stereocenters. Angew. Chem. Int. Ed. 46, 5488-5508, (2007).

238 3. Quasdorf, K. W.; Overman, L. E. Catalytic enantioselective synthesis of quaternary carbon 239 stereocenters. Nature 516, 181-191, (2014).

240 4. Li, C.; Ragab, S.; Liu, G.; Tang, W. Enantioselective formation of quaternary carbon stereocenters in natural product synthesis: a recent update. Nat, Prod. Rep. 37, 276-292, (2020).

5. Peterson, E. A.; Overman, L. E. Contiguous stereogenic quaternary carbons: A daunting challenge in natural products synthesis. PNAS 101, 11943-11948, (2004).

6. Long, R.; Huang, J.; Gong, J.; Yang, Z. Direct construction of vicinal all-carbon quaternary stereocenters in natural product synthesis. Nat. Prod. Rep. 32, 1584-1601, (2015).

246 7. Overman, L. E; Panone, D. V.; Stearns, B. A. Direct Stereo- and Enantiocontrolled Synthesis of 247 Vicinal Stereogenic Quaternary Carbon Centers. Total Syntheses of meso- and (-)-Chimonanthine and (+)-Calycanthine. J. Am. Chem. Soc. 121, 7702-7703, (1999). Carbon Stereocenters by the Intramolecular Heck Reaction. J. Org. Chem. 71, 2600-2608, (2006). 
251 9. De, S.; Das, M. K.; Roy, A.; Bisai, A. Synthesis of 2-Oxindoles Sharing Vicinal All-Carbon

252 Quaternary Stereocenters via Organocatalytic Aldol Reaction. J. Org. Chem. 81, 12258-12274, 253 (2016).

254 10. Trost, B. M; Osipov, M. Palladium-Catalyzed AsymmetricConstruction of Vicinal All-Carbon 255 Quaternary Stereocenters and its Application to the Synthesis of Cyclotryptamine Alkaloids. Angew. 256 Chem. Int. Ed. 52, 9176-9181, (2013).

257 11. Trost, B. M.; Malhotra, S.; Chan, W. H. Exercising Regiocontrol in Palladium-Catalyzed 258 Asymmetric Prenylations and Geranylation: Unifying Strategy toward Flustramines A and B. J. Am. Chem. Soc. 133, 7328-7331, (2011).

12. Ohmatsu, K.; Imagawa, N.; Ooi, T. Ligand-enabled multiple absolute stereocontrol in metalcatalysed cycloaddition for construction of contiguous all-carbon quaternary stereocentres. Nat. Chem. 6, 47-51, (2014).

13. Toro, A.; Nowak, P.; Deslongchamps, P. Transannular Diels-Alder Entry into Stemodanes: First Asymmetric Total Synthesis of (+)-Maritimol. J. Am. Chem. Soc. 121, 7702-7703, (1999). Colombiasin A. Angew. Chem. Int. Ed. 42, 1267-1270, (2003). Colombiasin A and (-)-Elisapterosin B: Application of the Cr-Catalyzed Asymmetric Quinone DielsAlder Reaction. Angew. Chem. Int. Ed. 44, 6046-6050, (2005).

16. Gao, L.; Hwang, G. S.; Ryu, D. H. Oxazaborolidinium Ion-Catalyzed Cyclopropanation of $\alpha$ Substituted Acroleins: Enantioselective Synthesis of Cyclopropanes Bearing Two Chiral Quaternary Centers. J. Am. Chem. Soc. 133, 20708-20711, (2011). 
273 17. Jolit, A.; Walleser, P. M.; Yap, G. P. A.; Tius, M. A. Catalytic Enantioselective Nazarov Cyclization: 274 Construction of Vicinal All-Carbon-Atom Quaternary Stereocenters. Angew. Chem. Int. Ed. 53, $275 \quad 6180-6183,(2014)$.

276 18. Liu, X.; Wang, P.; Bai, L.; Wang, L.; Yang, D.; Wang, R. Construction of Vicinal All-Carbon 277 Quaternary Stereocenters Enabled by a Catalytic Asymmetric Dearomatization Reaction of $278 \quad \beta$-Naphthols with 3-Bromooxindoles. ACS Catal. 8, 10888-10894, (2018).

279 19. Zheng, H.; Wang, Y.; Xu. C.; Lin, L.; Feng, X. Stereodivergent synthesis of vicinal 280 quaternaryquaternary stereocenters and bioactive hyperolactones. Nat. Commun. 9, 1968-1973, (2018).

20. Chen, S. K.; Ma, W. Q.; Yan, Z. B.; Zhang, F. M.; Wang, S. H.; Tu, Y. Q.; Zhang, X. M.; Tian, J. M. Organo-Cation Catalyzed Asymmetric Homo/Heterodialkylation of Bisoxindoles: Construction of Vicinal All-Carbon Quaternary Stereocenters and Total Synthesis of (-)-Chimonanthidine. J. Am. Chem. Soc. 140, 10099-10103, (2018). Annulation of Isoindigos with Allenes: Enantioselective Formation of Two Vicinal Quaternary Stereogenic Centers. Angew. Chem. Int. Ed. 58, 6260-6264, (2019).

22. Lanke, V.; Marek, I. Nucleophilic Substitution at Quaternary Carbon Stereocenters. J. Am. Chem. Soc. 142, 5543-5548, (2020). Stereogenic Centers within an Acyclic Chain. Angew. Chem. Int. Ed. 59, 36-49, (2020).

24. Movassaghi, M.; Schmidt, M. A. Concise Total Synthesis of (-)-Calycanthine, (+)-Chimonanthine, and (+)-Folicanthine. Angew. Chem. Int. Ed. 46, 3725-3728, (2007). Science 324, 238-241, (2009). 
26. Liang, K.; Deng, X.; Tong, X.; Li, D.; Ding, M.; Zhou, A.; Xia, C. Copper-Mediated Dimerization to Access 3a,3a-Bispyrrolidinoindoline: Diastereoselective Synthesis of (+)-WIN 64821 and (-)Ditryptophenaline. Org. Lett. 17, 206-209, (2015).

27. Shen, X.; Zhou, Y.; Xi, Y; Zhao, J.; Zhang, H. Copper catalyzed sequential arylation.oxidative dimerization of o-haloanilides: synthesis of dimeric HPI alkaloids. Chem. Common. 51, 1487314876, (2015).

28. Zong, L.; Tan, C. H. Phase-Transfer and Ion-Pairing Catalysis of Pentanidiums and Bisguanidiniums. Acc. Chem. Res. 50, 842-856, (2017).

29. Zhang, X.; Ren, J.; Tan, A. M.; Tan, D.; Lee, R.; Tan, C. H. An enantioconvergent halogenophilic nucleophilic substitution (SN2X) reaction. Science 363, 400-404, (2019).

30. Zefirov, N. S.; Makhonkov, D. I. X-Philic Reactions. Chem. Rev. 82, 615-624, (1982).

31. Sazonov, P. K. Nucleophilic substitution at the halogen atom (halogenophilic reactions Russ. Chem. Rev. 81, 317-337, (2012).

32. Ren, J.; Ban, X.; Zhang, X.; Tan, S. M.; Lee, R.; Tan, C. H. Kinetic and Dynamic Kinetic Resolution of Racemic Tertiary Bromides by Pentanidium-Catalyzed Phase-Transfer Azidation. Angew. Chem. Int. Ed. 59, 9055-9058, (2020).

\section{Acknowledgements}

314 We gratefully acknowledge financial support from Nanyang Technological University for Tier 1 grants 315 (RG1/19 and RG2/20) and Ministry of Education (Singapore) Tier 2 grants (MOE2019-T2-1-091). We 316 We also like to acknowledge financial support from the University of Wollongong (VC Fellowship) and 317 Australian Research Council (DECRA DE210100053). This work was supported by the A*STAR 318 Computational Resource Centre through the use of its high performance computing facilities. 


\section{Author contributions}

$320 \mathrm{Xu}$ Ban performed the condition optimization, investigated the scope of the substrates, and conducted the

321 experimental mechanistic studies. Yifan Fan and Tuan-Khoa Kha synthesized the bromides and tertiary

322 carbon nucleophiles. Choon Wee Kee and Richmond Lee performed the computational study of the

323 obsolutle configuration for vicinal tertiary and quaternary all-carbon centers. Zhiyong Jiang participated

324 in the design and discussion of the mechanistic experiments. Choon Hong Tan directed the project and

325 wrote the manuscript. All authors analyzed the results and commented on the manuscript.

326 Corresponding author

327 Correspondence to Prof. Choon-Hong Tan

\section{Competing interests}

329 The authors declare no competing interests. 
Figures

(a) Major previous strategies

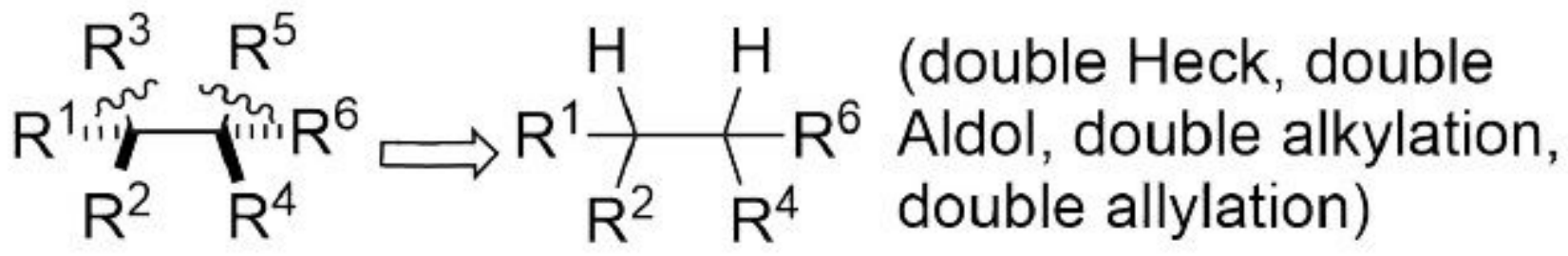

vicinal quaternary

all-carbon

stereocenters

$\mathrm{R}^{1} \mathrm{R}^{3}$
$\mathrm{R}^{3}$

(b) Radical dimerizations

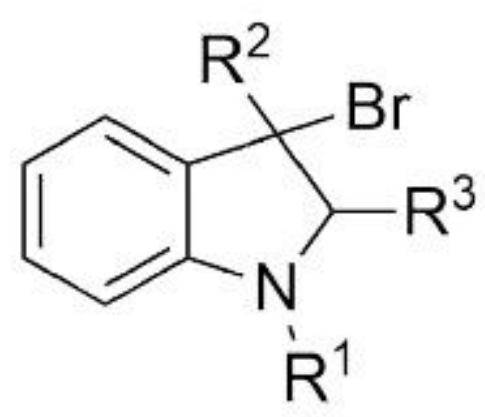

$\stackrel{\mathrm{Co} \text { or } \mathrm{Cu}}{\longrightarrow}$

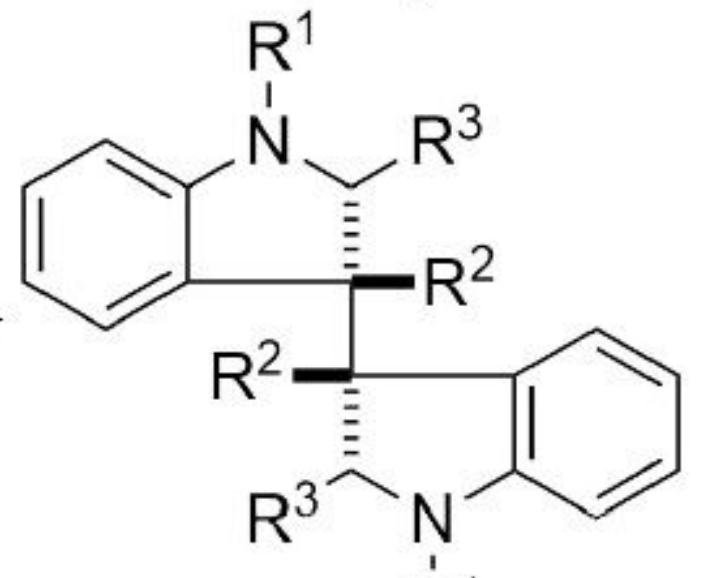

$\mathrm{R}^{1}$

(c) This work: direct $\mathrm{C}\left(\mathrm{sp}^{3}\right)-\mathrm{C}\left(\mathrm{sp}^{3}\right)$ coupling
$\mathrm{R}^{1} \mathrm{R}^{6}$
$R^{1}$
$\mathrm{R}^{6}$
$R^{3}$.)
$R^{2} \quad R^{4}$
$\left.R^{3}\right)$
$R^{2}$
$-R^{5}$
$\mathrm{R}^{4}$

Figure 1

Major Strategies for Construction of Vicinal All-Carbon Quaternary Stereocenters 


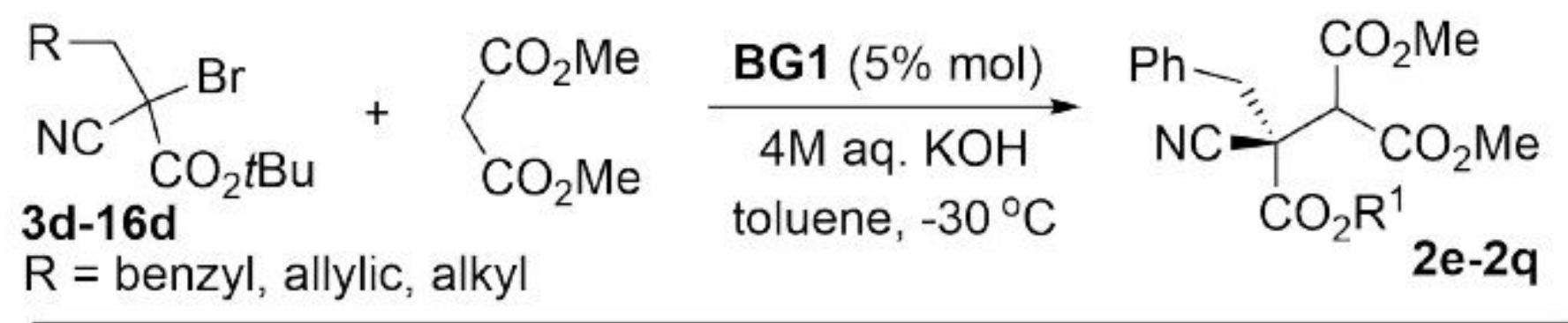

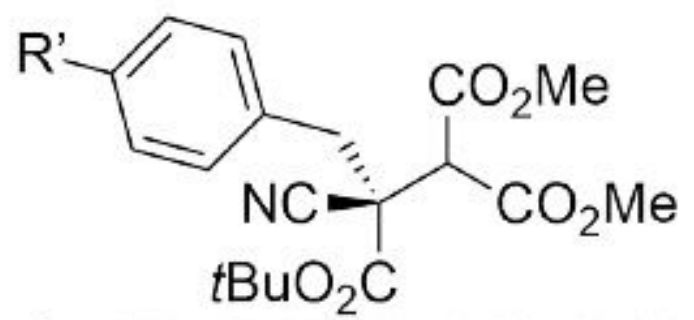

2e, $R^{\prime}=F ; 75 \%$ yield, $96 \%$ ee

2f, $\mathrm{R}^{\prime}=\mathrm{Cl} ; 75 \%$ yield, $90 \%$ ee

$\mathbf{2 g}, \mathrm{R}^{\prime}=\mathrm{Br} ; \mathbf{7 7} \%$ yield, $92 \%$ ee

$2 \mathrm{~h}, \mathrm{R}^{\prime}=\mathrm{NO}_{2} ; 70 \%$ yield, $88 \%$ ee

$\mathbf{2 i}, \mathrm{R}^{\prime}=$ OMe; $77 \%$ yield, $90 \%$ ee

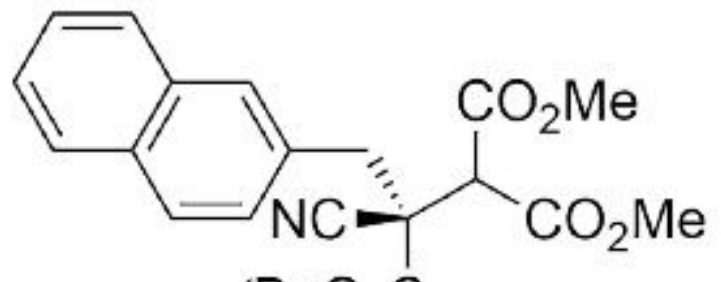

$t \mathrm{BuO}_{2} \mathrm{C} \quad 2 \mathrm{j}: 72 \%$
$\left\langle\mathrm{N}=\mathrm{CO}_{\mathrm{NBO}} \mathrm{Me}\right.$

2I: $67 \%$ yield, $88 \%$ ee

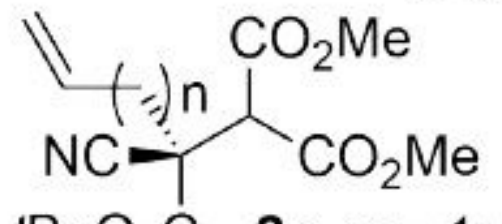

$t \mathrm{BuO}_{2} \mathrm{C} \quad 2 \mathrm{o}, \mathrm{n}=1 ; 80 \%$ yield, $92 \%$ ee $2 p, n=3 ; 80 \%$ yield, $86 \%$ ee

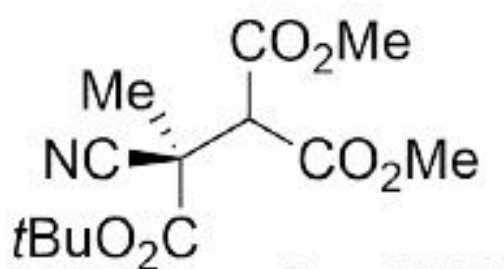

2m: $78 \%$ yield, $90 \%$ ee
$\mathrm{CO}_{2} \mathrm{Me}$ yield, $92 \%$ ee

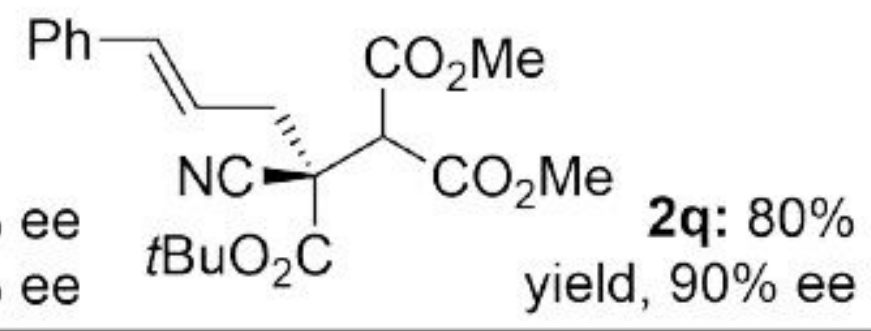

\section{Figure 2}

Synthesis of Isolated All-Carbon Quaternary Stereocenters. Unless otherwise noted, the reactions were carried out with BG1 (5 mol \%), 4M aq. $\mathrm{KOH}(0.07 \mathrm{mmol})$, tertiary bromides $3 \mathrm{~d}-16 \mathrm{~d}(0.05 \mathrm{mmol})$, dimethyl malonate $(0.06 \mathrm{mmol})$ in toluene $(2 \mathrm{~mL})$ at $-30 \mathrm{oC}$ for 2-3 days. Isolated yields are reported. The ee values were determined by HPLC analysis on chiral stationary phase. Absolute configuration was determined using an X-ray crystal structure of 2l. $\mathrm{HCl}$ (See SI, page 80). 
$\mathrm{NC}_{\mathrm{CO}_{2} t \mathrm{Bu}}^{\mathrm{Br}}+\sum_{\mathrm{CO}_{2} t \mathrm{Bu}}^{\mathrm{CO}_{2} \mathrm{Me}}$

4d-5d, 7d, 9d,

11d-14d

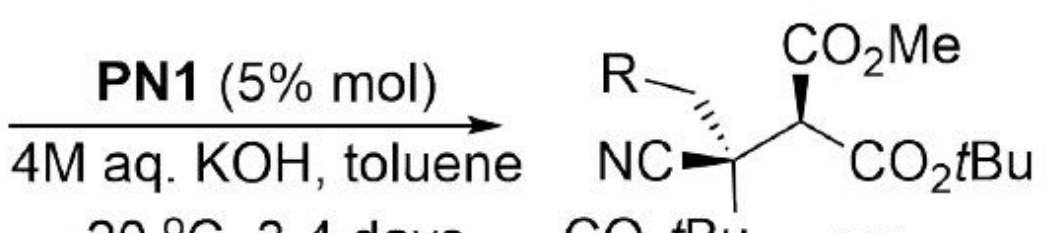

$-20^{\circ} \mathrm{C}, 3-4$ days $\quad \mathrm{CO}_{2} t \mathrm{Bu} \quad$ 19l-s

$\mathrm{R}=$ benzyl, allylic or alkyl

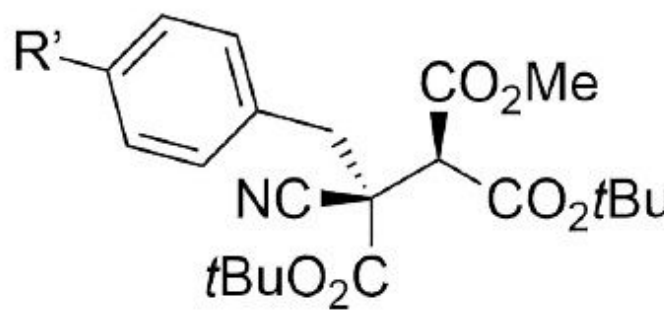

$\mathrm{ABO}_{2} \mathrm{C}$

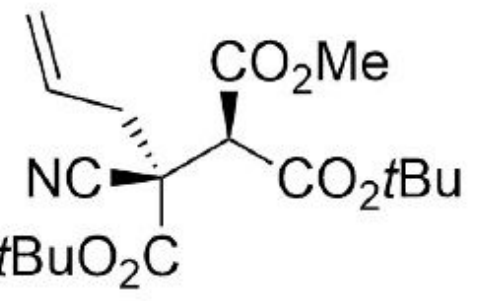

19l, R' = Cl; 79\% yield, $90 \%$ ee, $32: 1 \mathrm{dr}$ $19 \mathrm{~m}, \mathrm{R}^{\prime}=\mathrm{Br} ; 82 \%$ yield, $90 \%$ ee, $32: 1 \mathrm{dr}$ 19n, R' = OMe; $80 \%$ yield, $96 \%$ ee, $9: 1 d r$ 19p: $81 \%$ yield $89 \%$ ee, $13: 1 \mathrm{dr}$

$19 s, 84 \%$ yield $86 \%$ ee, $16: 1 d r$<smiles>CCOC(=O)[C@H](Cc1cccs1)C(C)(C)C</smiles>
$\mathrm{tBuO}_{2} \mathrm{C}$ 19o: $76 \%$ yield, $95 \%$ ee, $4: 1 \mathrm{dr}$<smiles></smiles>
$t \mathrm{BuO}_{2} \mathrm{C}$

19q, $n=2 ; 82 \%$ yield $94 \%$ ee, $19: 1 \mathrm{dr}$ $19 r, \mathrm{n}=3 ; 80 \%$ yield $93 \%$ ee, $9: 1 d r$

Figure 3

Synthesis of Vicinal Tertiary and All-Carbon Quaternary Stereocenters. Unless otherwise noted, the reactions were carried out with PN1 (5 mol \%), 4M aq. $\mathrm{KOH}(0.05 \mathrm{mmol})$, tertiary bromides $(0.05 \mathrm{mmol})$, malonate $18 \mathrm{~d}(0.06 \mathrm{mmol})$ in toluene $(2 \mathrm{~mL})$ at $-20 \mathrm{oC}$ for 3-4 days. Isolated yields are reported. The $\mathrm{dr}$ value was determined by HPLC analysis. The ee values were determined by HPLC analysis on chiral stationary phase. Absolute configuration was determined using an X-ray crystal structure of a derivative and DFT calculation (See SI, page 81). 

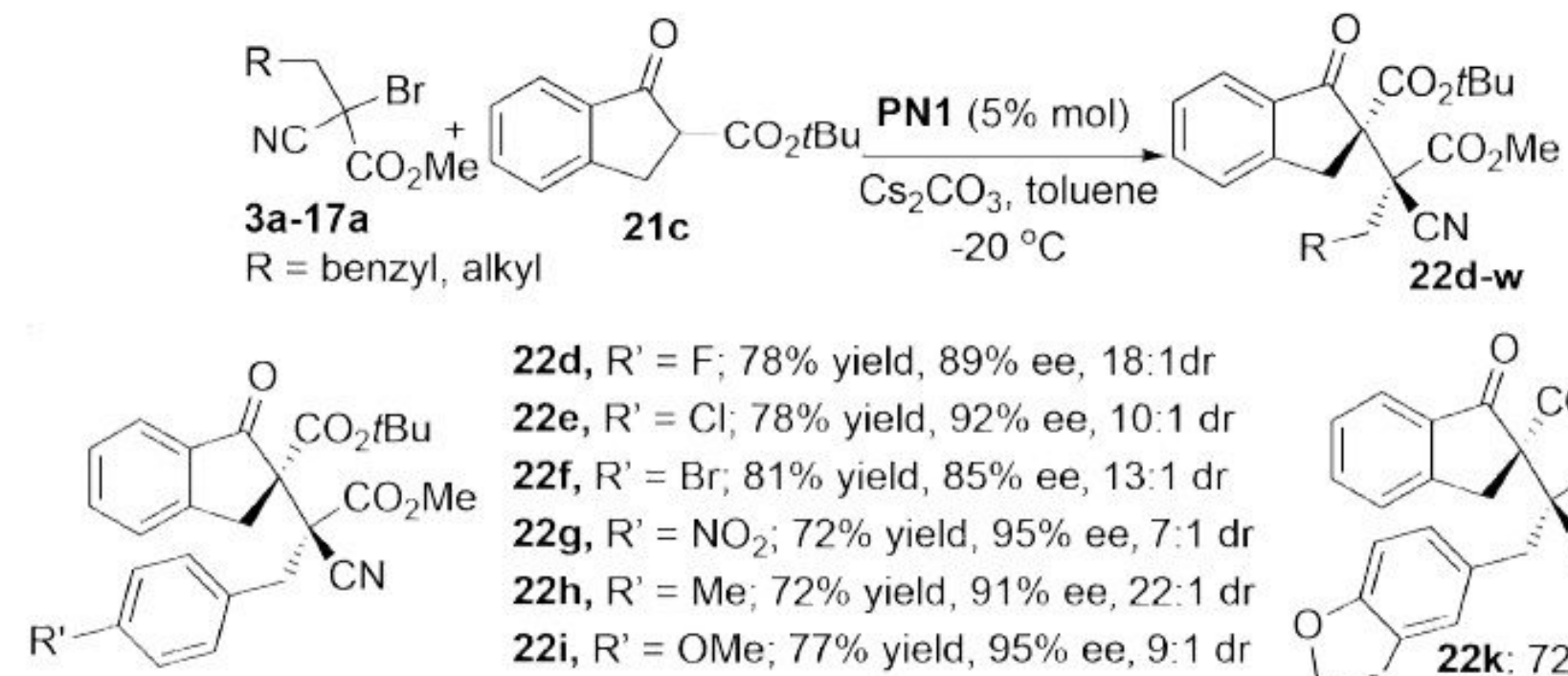

22d, R' $=F ; 78 \%$ yield, $89 \%$ ee, $18: 1 d r$ 22e, $\mathrm{R}^{\prime}=\mathrm{Cl} ; 78 \%$ yield, $92 \%$ ee, $10: 1 \mathrm{dr}$ 22f, R' $=\mathrm{Br}$; $81 \%$ yield, $85 \%$ ee, $13: 1 \mathrm{dr}$ 22g, R' $=\mathrm{NO}_{2} ; 72 \%$ yield, $95 \%$ ee, $7: 1 \mathrm{dr}$ 22h, R' $=$ Me; $72 \%$ yield, $91 \%$ ee, $22: 1 \mathrm{dr}$ 22i, R' = OMe; $77 \%$ yield, $95 \%$ ee, $9: 1 \mathrm{dr}$<smiles>CCOC(=O)C1(C#N)Cc2ccccc2C1=O</smiles>
$22 \mathrm{j}, \mathrm{R}^{\prime}=\mathrm{SMe} ; 77 \%$ yield, $90 \%$ ee, $9: 1 \mathrm{dr}$

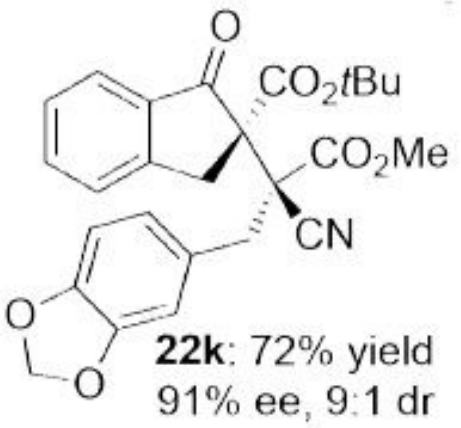
221: $72 \%$ yield

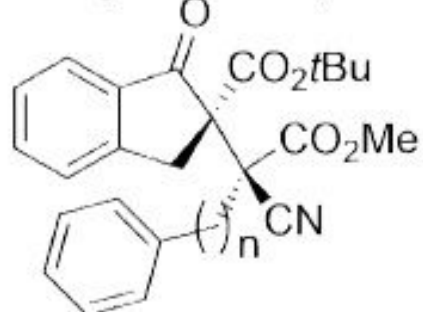
$22 \mathrm{~m}, \mathrm{n}=3 ; 76 \%$ yield

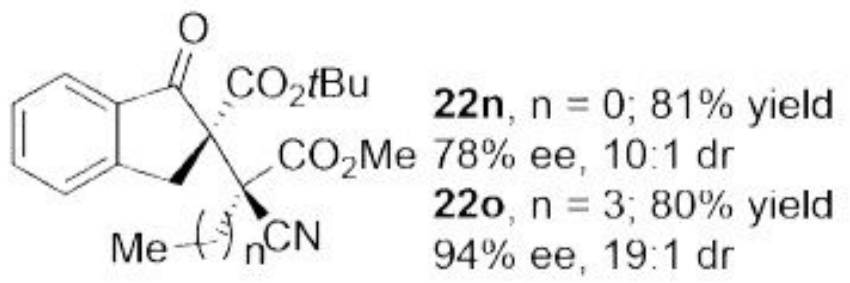
$89 \%$ ee, $15: 1 \mathrm{dr}$<smiles>CCOC(=O)C(C)(C(C)C)[C@]1(C(OCC)C(C)C)Cc2ccccc2C1=O</smiles>

$96 \%$ yield, $87 \%$ ee, $13: 1 \mathrm{dr}$<smiles>CCOC(=O)C1(C(C#N)C(C)C)Cc2cc(C)ccc2C1=O</smiles>

$22 t, n=2$;

$76 \%$ yield, $88 \%$ ee, $9: 1 \mathrm{dr}$ 22q $78 \%$ yield $98 \%$ ee, $12: 1 \mathrm{dr}$<smiles>CCCOC(=O)[C@]1([C@@](C#N)(CC2CCCCC2)C(=O)OC)Cc2cc(C)ccc2C1=O</smiles>

22r $74 \%$ yield $91 \%$ ee, $16: 1 \mathrm{dr}$

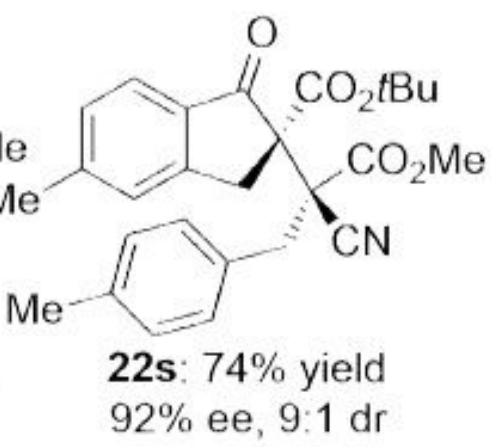

22u, R" = Me; $81 \%$ yield, $91 \%$ ee, $10: 1 \mathrm{dr}$ $22 \mathrm{v}, \mathrm{R}^{\prime \prime}=\mathrm{OMe} ; 82 \%$ yield, $90 \%$ ee, $11: 1 \mathrm{dr}$ $22 \mathrm{w}, \mathrm{R} "=\mathrm{Cl} ; 80 \%$ yield, $83 \%$ ee, $5: 1 \mathrm{dr}$

\section{Figure 4}

Synthesis of Vicinal All-Carbon Quaternary Stereocenters. Unless otherwise noted, the reactions were carried out with PN1 (5 mol \%), Cs2CO3 $(0.07 \mathrm{mmol}), 1 \mathrm{a}(0.05 \mathrm{mmol}), 21 \mathrm{c}(0.06 \mathrm{mmol})$ in toluene $(2 \mathrm{~mL})$ at -20 oC for 3-4 days. Isolated yield. The dr value was determined by HPLC analysis. The ee value was determined by HPLC analysis on chiral stationary phase. Absolute configuration was determined using an X-ray crystal structure of 22c (See SI, page 85). 


\section{Supplementary Files}

This is a list of supplementary files associated with this preprint. Click to download.

- NCommvicqCSI.pdf 